\title{
EXCHANGE CHARACTERISTICS OF AN ANTHROPOGENICALLY MODIFIED LAGOON: AN EULERIAN-LAGRANGIAN MODELING CASE STUDY WITH AN EMPHASIS ON THE NUMBER OF PARTICLES
}

\author{
Banu TANSEL BÜYÜKÇELEBI ${ }^{1}$, Hasan KARABAY², Ata BILGILI ${ }^{*}$ \\ ${ }^{1}$ Maritime Faculty, Istanbul Technical University, Tuzla, 34940 Istanbul, Turkey \\ ${ }^{2}$ Department of Mechanical Engineering, Kocaeli University Umuttepe Yerleşkesi, 41380 Kocaeli, Turkey
}

Received 21 February 2020; accepted 16 April 2021

\begin{abstract}
Highlights
We initialize the study of an unstudied lagoon ecosystem that has a large potential to be used as an example setting, allfield study ground for anthropogenically engineered coastal domains.

$>$ We present a practical and relatively simple methodology based to quantify a Lagrangian particle release simulation's convergence in exchange calculations.

$>$ We present a particle tracking justification method based on confidence levels that can be used in the absence of measurements.

We highlight how Eulerian and Lagrangian methods can complement each other.

$>$ We show how the scientific methods can stay in the loop in fund-depleted decision processes that would otherwise be arbitrary and haphazard.
\end{abstract}

\begin{abstract}
The transport pathways and exchange characteristics of the Kamil Abdüş Lagoon in Istanbul, Turkey, are simulated using a finite element model with a Lagrangian particle tracking module. The lagoon is in the process of being reconfigured. The simulations are performed using a draft configuration. The effect of winds and the number of particles on the e-folding time is simulated. Results show that the lagoon is strongly dominated by winds with a correlation coefficient of 0.897 between the wind and residual current magnitudes. The lagoon e-folds in 9.1 days under realistic winds and in 14.3 days when there is no wind with confidence levels of $5 \%$. The Lagrangian study uses six simulations with particle numbers ranging between 65073 and 2730486. A methodology based on confidence levels is proposed. It is observed that approximately 784000 particles are necessary to obtain 5\% level of confidence. With a problematic history and new planning options, the lagoon has a potential to be used as an example setting, all-field study ground for anthropogenically engineered coastal ecosystems.
\end{abstract}

Keywords: particle tracking, number of particles, Lagrangian, exchange, residence time, wind, restoration, lagoon, numerical model, Tuzla.

\section{Introduction}

The Kamil Abdus Lagoon (Lagoon hereafter) in the Tuzla district of Istanbul, Turkey (Figures 1 and 2), showed typical characteristics of a small and dynamic coastal lagoon until 1978, when a decision was made to make the area home for a growing shipyard industry. A series of ecologically insensitive decisions then followed, including landfills that closed the natural inlet, channeling of streams that carry fresh water into the lagoon and construction of a roadway that completely isolated the lagoon from the Sea of Marmara. As a result, the lagoon first became a boggy freshwater pond subject to heavy rates of nutrient pollution and then completely dried in 2001 and became a waste land. In 2006, the local municipality initiated a rehabilitation project to restore the lagoon as much as possible to its original dynamics, as the lagoon has vast potential to contribute to the socio-economical growth of the region. The project included dredging for overall deepening, creation of a network of deeper channels and surrounding flats and opening up two inlets to

${ }^{*}$ Corresponding author. E-mail: bilgili@itu.edu.tr 
refill the lagoon with salt water, also allowing exchange with the Sea of Marmara. The construction of three islands was also considered as a refuge for once abundant bird population to settle away from human interaction and for local vegetation to grow. Since the proposed actions were extensive and new physical formations were going to be introduced into the lagoon, questions were raised as to how much time would be required for the lagoon to flush itself and how sensitive this would be to dominant weather conditions. The problem is amplified by two possible sources of pollution: the shipyards located just north of the lagoon and the existence of a wastewater treatment facility located just southeast of the lagoon (Figure 2). The latter is especially important since it is subject to overflows and there is the possibility of the discharge being transported towards land due to dominating winds. For an excellent review of the event history of the lagoon, the reader is referred to Ozturk (2005).

Presently, the rehabilitation of the area is still at the planning stages and several options are considered including but not limited to keeping the lagoon as a natural reserve open to public, using it for aquaculture or building a marina inside, all of which would require thorough environmental and engineering investigations. The previous published work on the lagoon, however, is almost non-existent and very few existing studies by engineering firms are mostly unobtainable. Extensive research should be performed before any decision can be made as to how to effectively use the lagoon without any further environmental damage. In this sense, the lagoon provides a previously unstudied exciting field with a potential to offer number of opportunities to investigate short-term and long-term anthropogenic effects on similar coastal environments.

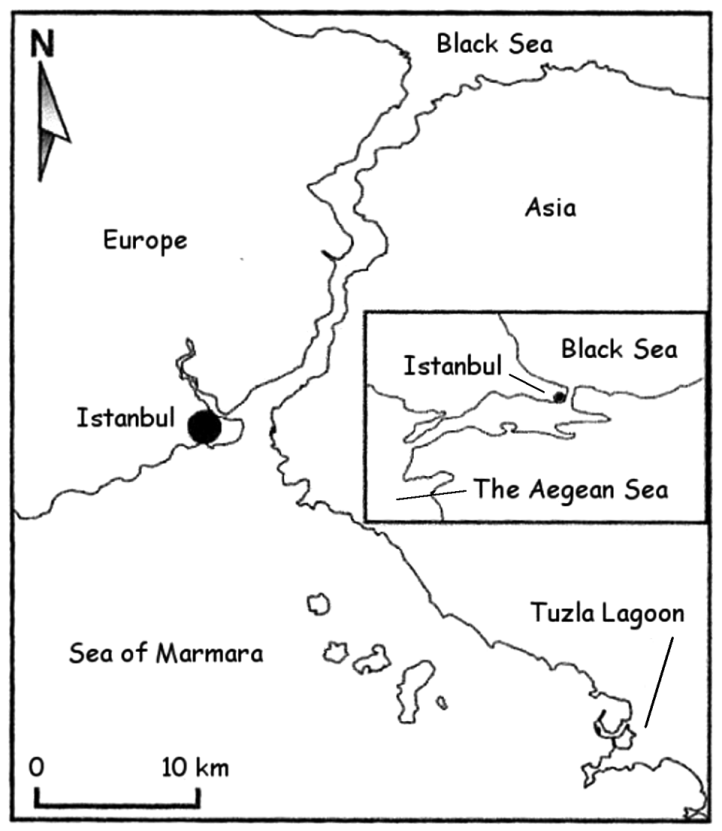

Figure 1. The location map of the Tuzla Kamil Abdus Lagoon. Redrawn from Ozturk (2005)
The overall purpose of the current paper is to present an initial effort to estimate the exchange properties of this more or less unstudied lagoon with the Sea of Marmara, given the proposed channel configuration and island placement. A secondary purpose is to present a simple method to quantify the "statistically significant" term often used in particle tracking simulations (Bilgili et al., 2005; Delhez et al., 2014; Harms et al., 2003; Hoyer et al., 2014; Qin et al., 2014). A vertically averaged model incorporating a Lagrangian transport module is used to simulate the hydrodynamics and related particle movement. Overall transport pathways and the wind dominance are investigated using an Eulerian point of view. To complement the Eulerian study, passive particles with no individual behavior are tracked over a month and $e$-folding times are calculated for given wind conditions. The effect of the number of particles on the $e$-folding time, defined as the time it takes to decrease the number of particles initially in the lagoon by a factor of $e$, is also investigated and a straightforward quantitative methodology is proposed. The latter is a task seldom carried out due to its expensive use of computer resources and time and we believe that any contribution in this arena is a step forward towards new approaches to evaluate the results of Lagrangian particle simulations.

\section{Methodology}

The methods used are typical of similar modeling studies. These consist of discretizing the physical domain, setting up the independent and dependent parameters, assembling the boundary conditions, and formulating or choosing a suitable model for simulating the particle movement and the underlying hydrodynamics. These are detailed in the following subsections.

\subsection{The simulation domain and its discretization}

The simulation domain consists of the lagoon itself and the coastal section of the Sea of Marmara in its close vicinity (Figure 2, left). The lagoon proper is a shallow reservoir of water with three engineered islands (Figure 2, right). There is an encircling deeper channel with two finite branches that extend between the islands (solid lines in Figure 2, right). The channel depths are on the order of 2.5 meters. The surrounding flats are approximately 1.2 meters deep. The bottom consists of a combination of muddy and sandy sediments with no rocky structures and very little vegetation due to recent refilling. The channels are connected to two $3.5 \mathrm{~m}$ deep dredged inlets through which the exchange with the Sea of Marmara occurs. To reproduce a natural evolution, the bathymetric transition between the deeper channels and the flats occurs through a $10 \mathrm{~m}$ wide zone where depths change randomly around the line connecting the limiting values of 2.5 and 1.2 meters. The values obey a normal distribution with a mean of $1.85 \mathrm{~m}$ and a standard deviation of 0.4925 . 

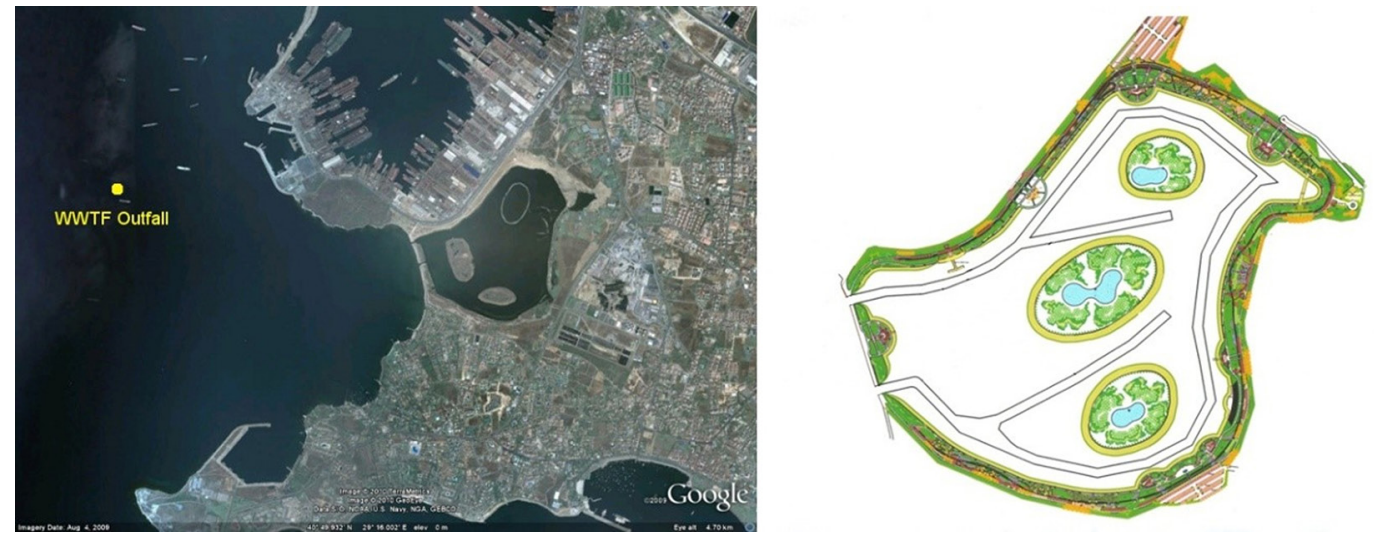

Figure 2. The modeling domain. The figure on the left shows the current condition while the drawing on the right is the simulated configuration. The yellow dot on the figure on the left shows the approximate location of the WWTF outfall (Picture credits: Left, Google Maps. Right, Municipality of the Town of Tuzla, Istanbul, Turkey)

The section of the coastal sea that is included in the model was chosen to include the existing outfall of the local tertiary wastewater treatment facility (WWTF) for future investigations. The treatment facility, located just southeast of the lagoon (Figure 2), has a discharge rate of $500,000 \mathrm{~m}^{3} \cdot \mathrm{day}^{-1}$ and serves an area with a population of approximately 2.5 million people. The open sea bathymetry is digitized from the Navigational Chart \#2919 of the Turkish Department of Navigation, Hydrography and Oceanography. It should be noted that the actual location of the islands constructed after this study differ between the simulated configuration (Figure 2, right) and the most recent Google Maps picture (Figure 2, left), the latter shown to provide a general view of the area as it presently is. The island locations were modified haphazardly to have a larger open water area further inland during the implementation of the plan. This arbitrary move is expected to modify the exchange results presented in this study since the islands will likely act barriers due to their closer location to the inlets, trapping a larger portion of the lagoon's water.
The domain is discretized using a finite element grid consisting of 15347 nodes and 29387 linear triangular elements (Figure 3). The channels and the inlets are further refined by imposing enforced nodes to resolve the flow in and out of them. The quality of the overall grid was guaranteed by imposing a minimum inside angle of $30^{\circ}$ using BatTri (Bilgili et al., 2006). The element quality is calculated by

$$
q=\frac{4 \sqrt{3} A}{L_{1}^{2}+L_{2}^{2}+L_{3}^{2}},
$$

where $q$ is the element quality measure, $A$ is the element area and $L_{1}, L_{2}$ ve $L_{3}$ are the lengths of the sides of the triangle. For more than $95 \%$ of the grid, $q$ is between 0.9 and 1 with an overall average of 0.94 and a minimum of 0.55 at one triangle along the open sea boundary. The characteristic length $L=\sqrt{2 A}$ of the smallest triangle is $0.10 \mathrm{~m}$ in the lagoon and $153 \mathrm{~m}$ in the open sea with an average of $11.7 \mathrm{~m}$. Finally, the available bathymetry is linearly interpolated onto this grid (Figure 4). The details of the grid generation process can be found in Tansel (2010).

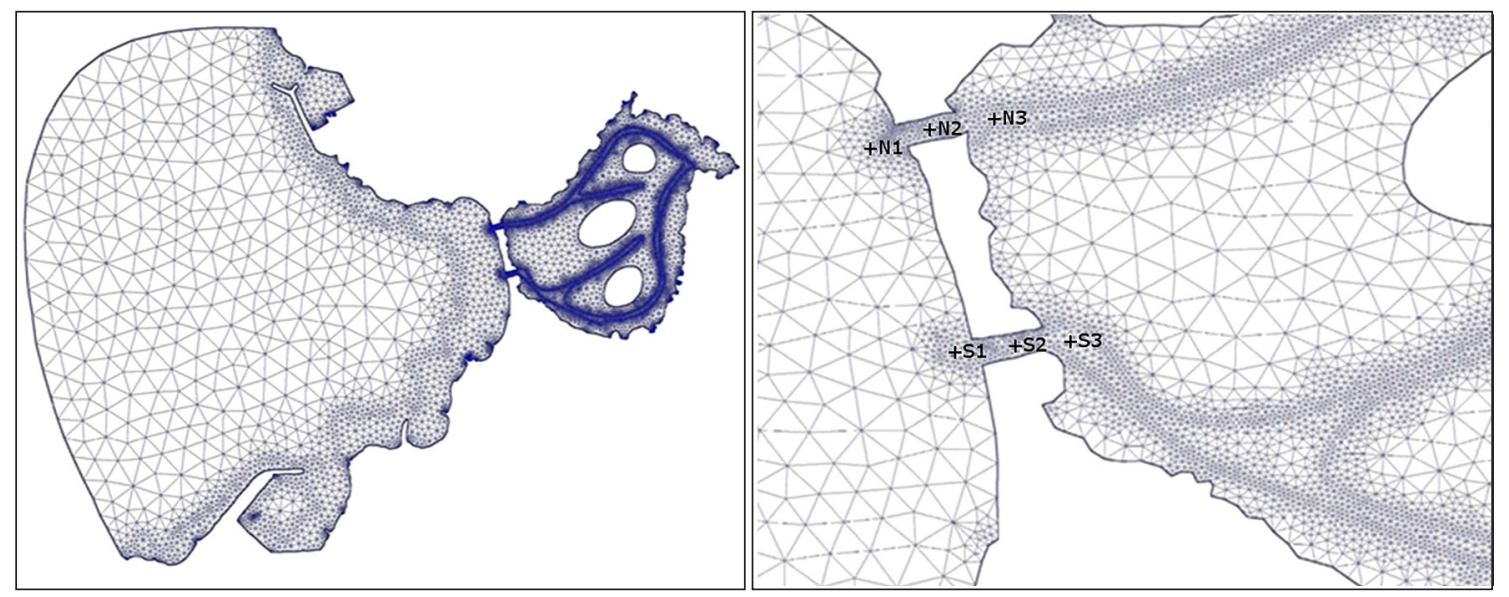

Figure 3. The computational finite element grid of the study area. The figure on the right zooms in to the inlet section of the lagoon to show detail. Locations of current recording stations (N1, N2, N3, S1, S2, S3) are also marked 

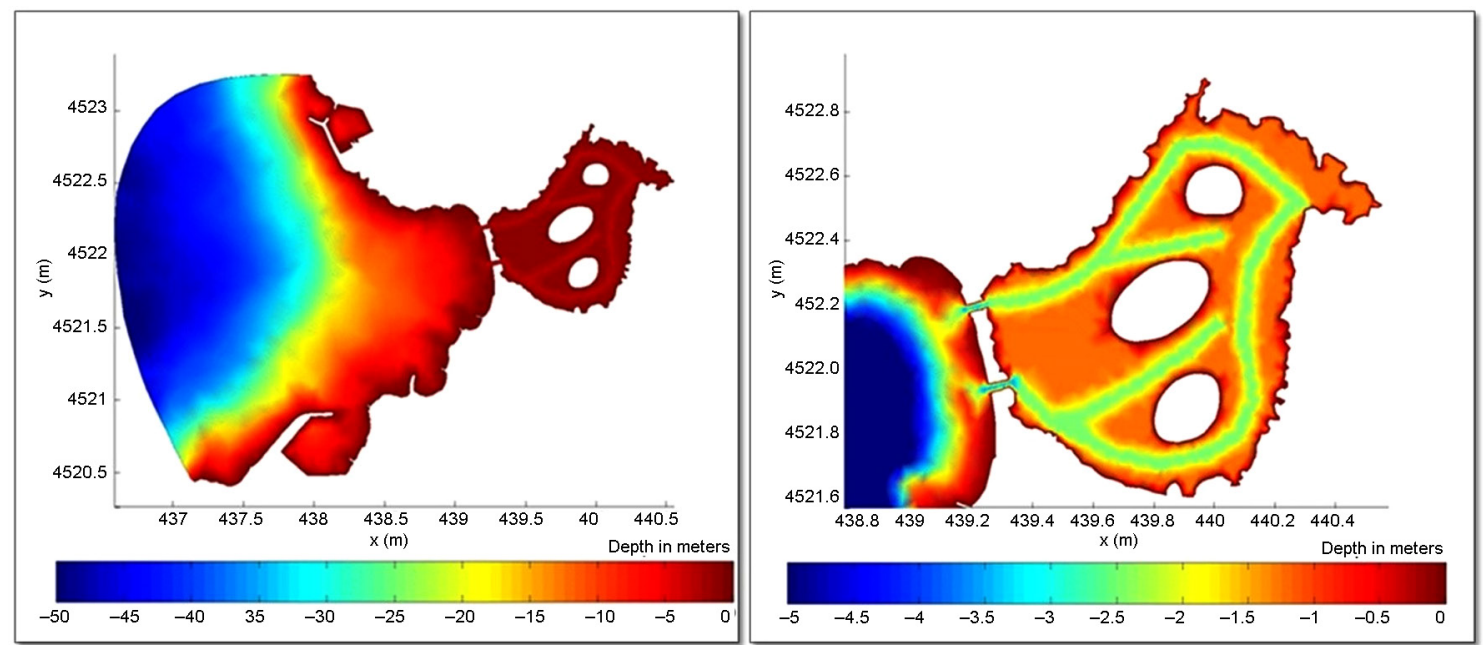

Figure 4. Grid bathymetry of the domain. The axes are in meters. The color bars show depths in meters below the mean water level. The figure on right zooms in to the lagoon proper to show detail. The depths are referenced to the mean sea level

\subsection{The physical conditions}

With tides on the order of a few centimeters and the lack of freshwater input, wind forcing is expected to dominate the circulation patterns and transport in the lagoon. An analysis of the continuous wind data, acquired from the Turkish State Meteorological Service (TSMS) between June 1975 and June 2006, shows that the strongest winds in the region occur during winter months and especially in February. We use winds from February 2001 (Figure 5) to drive the wind module of the model since this data set proved to be the most reliable and include typical seasonal winds up to Beaufort 5 with no episodic gales. The dominant winds are the southwesterlies (blowing towards $25^{\circ}$

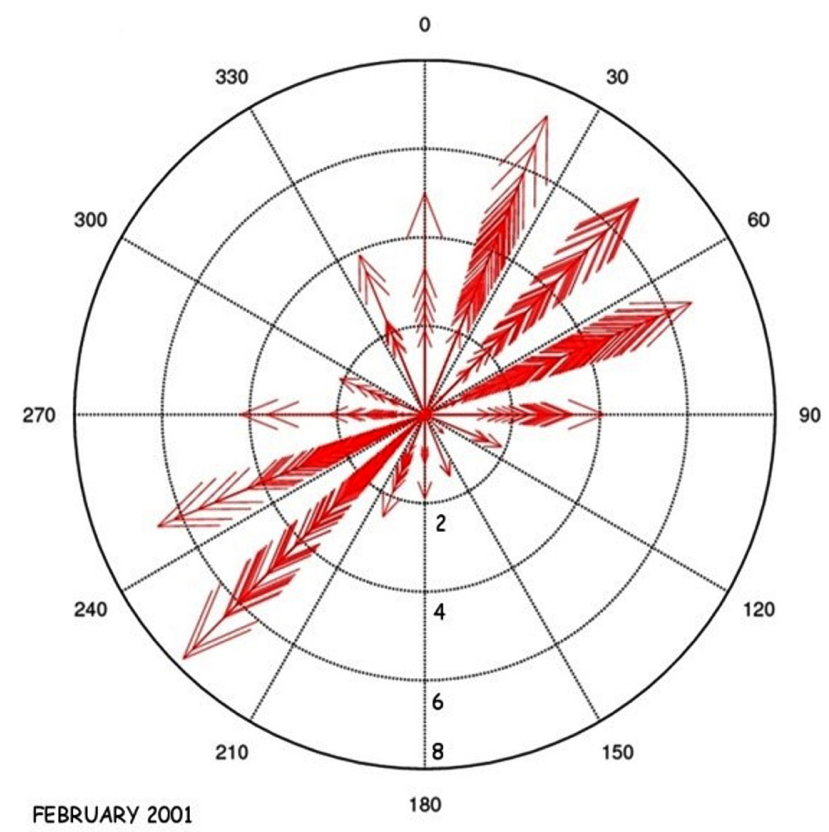

Figure 5. Wind vectors for the month of February, 2001. The vectors are shown using $22.5^{\circ}$ bins for clarity. The circular increments are $2 \mathrm{~m} / \mathrm{s}$ each and $65^{\circ}$ ), followed by the northeasterlies (blowing towards directions ranging between $225-245^{\circ}$ ). To put the wind speeds used in this study in perspective, Ozbahceci (2020) did some extreme wind speed values statistics analyses using data measured by two buoys set up by the TSMS near the study area in 2013. The results from approximately 5 years of measurements showed that the extreme wind speeds in the study region are roughly between of $21.5 \mathrm{~m} / \mathrm{s}$ and $25.9 \mathrm{~m} / \mathrm{s}$ for 30 and 100-year events respectively. These values are approximately three times higher than the maximum winds used in this study. Although small, we still include the $\mathrm{M}_{2}, \mathrm{~S}_{2}, \mathrm{~K}_{1}$ and $\mathrm{O}_{1}$ tidal components in the calculations as reported by Alpar and Yuce (1998) for thoroughness (Table 1). These correspond to a spring range of approximately $5 \mathrm{~cm}$ and a neap range of less than $1 \mathrm{~cm}$, which is consistent with the values simulated by Ferrarin et al. (2018).

\subsection{The model}

The shallow depths and the absence of freshwater input allow a two dimensional depth averaged model to be used for simulating the overall well-mixed hydrodynamics in the lagoon (Dias et al., 2001). Furthermore, the rainfall events common during the time of the simulation (February) are associated with winter storms that produce high winds resulting in high mixing in the lagoon. Therefore, the overall effect would be a salinity reduction over the entire domain rather than stratification. In shallow areas where the total depth is less than $0.5 \mathrm{~m}$, the force balance is assumed to be between the tidal pressure gradient, the wind stress and the bottom stress resulting in the following governing set of equations:

$$
\begin{aligned}
& \frac{\partial H}{\partial t}+\nabla \cdot \mathbf{Q}=0 ; \\
& \mathbf{g} H \nabla \zeta+\frac{C_{d}}{H^{2}}|\mathbf{Q}| \mathbf{Q}=\mathbf{W},
\end{aligned}
$$


where: $H$ is the total depth, $t$ is time, $\mathbf{Q}=H \cdot \mathbf{V}$ is the volumetric flux, $\mathbf{V}$ is the depth averaged velocity, $\mathbf{g}$ is the gravitational acceleration, $\zeta$ is the surface elevation relative to the mean sea level, $C_{d}$ is the bottom drag coefficient, and $\mathbf{W}$ is the kinematic wind stress, given by

$$
\frac{\tau_{\mathbf{w}}}{\rho_{a}}=\left.v \frac{\partial \mathbf{U}_{\mathbf{w}}}{\partial z}\right|_{z=0}=C_{w}\left|\mathbf{U}_{\mathbf{w}}\right| \mathbf{U}_{\mathbf{w}},
$$

where $\tau_{\mathbf{w}}$ is the quadratic wind stress, $\rho_{a}=1.25 \mathrm{~kg} \cdot \mathrm{m}^{-3}$ is the air density, $\mathrm{v}$ is the kinematic viscosity of water, $z$ is the vertical coordinate, $C_{w}$ is the wind drag coefficient and $\mathbf{U}_{\mathbf{w}}$ is the wind velocity $10 \mathrm{~m}$ above sea level. The wind drag coefficient $C_{w}$ is taken as $\left(0.8+0.065 \cdot \mathbf{U}_{\mathbf{w}}\right) \cdot 10^{-3}$ after $\mathrm{Wu}$ (1982), with an upper limit of 0.002. The bottom stress, in its turn, is parameterized using a three-regime drag coefficient. In areas deeper than $25 \mathrm{~m}$, the $C_{d}$ is set to a standard open ocean constant value of 0.0025 . In areas shallower than $10 \mathrm{~m}$, a value of 0.01 is used to account for increased drag. In all areas in-between, the $C_{d}$ changes linearly between these two limiting values. It should be noted that these correspond to a Chezy number range of $[31,62]$ and a Manning's $n$ range of $[0.027$, 0.047], both within acceptable ranges given by Zheng et al. (2013) for 2-D models. This diffusive force balance is coupled to a Darcian equation to represent wetting and drying by way of an underlying porous layer, as detailed in Ip et al. (1998).

In deeper areas where the total water depth reaches a value of $0.5 \mathrm{~m}$, the momentum equation (Eq. (2)) is modified to include the local accelerations (McLaughlin et al., 2003):

$$
\frac{\partial \mathbf{Q}}{\partial t}+\mathbf{g} H \nabla \zeta+\frac{C_{d}}{H^{2}}|\mathbf{Q}| \mathbf{Q}=\mathbf{W}
$$

It should be noted here that this threshold of $0.5 \mathrm{~m}$ is just a switching depth to the kinematic physics from the dynamic physics as the tide progresses onto the flats and shallows where the effect of bottom friction amplifies. It has no connection with the typical classification of water waves as shallow or deep as any tide would be classified as a shallow wave at these depths. The threshold is based on the calibration analyses and has been proven to work in different domains (Fugate et al., 2006; Swanson et al., 2015; Bilgili et al., 2016). The effect of the advective accelerations is expected to be negligible since the lagoon is engineered and the channel geometry is rather constant. This simplified model has the necessary physics to simulate shallow, well-mixed estuaries and lagoons where the bottom stress, the wind stress, the pressure gradient and the local accelerations dominate the overall flow regime. It also has the additional advantage of speeding up the calculations since the acceleration term is ignored where the grid elements are smaller. The computer model summarized above, called Bellamy, has been tested extensively in the past in studies involving tidal rivers (Swanson et al., 2015; Bilgili et al., 2016) and shallow tidal flats and lagoons (Erturk et al., 2002; Fugate et al., 2006). The reader is referred to the original papers by Ip et al. (1998) and McLaughlin et al. (2003) for the details of the computer model.

The hydrodynamic model is coupled to a time stepping Lagrangian particle tracking module, Drog3Ddt (Blanton, 1995), which uses a standard $4^{\text {th }}$ order Runge-Kutta advection scheme, complemented by a random walk module to simulate turbulent dispersion. The well-documented algorithm has been in extensive use since the mid-nineties and applications include fisheries, tidal dispersion, sediment transport and wastewater studies (Bilgili et al., 2003; Larson et al., 2003; Edwards et al., 2006). The implementation here uses only one vertical layer to be consistent with the underlying vertically averaged flow field provided by Bellamy. The module is parallelized using the Message Passing Interface (MPI), which allows a "statistically significant" number of particles to be tracked in time. To investigate the sensitivity of the results to the number of particles, we use six sets of particles covering the entire domain. The properties of these simulations are given in Table 2. An arresting boundary condition (Lynch et al., 2015) makes sure that if a particle tries to cross a boundary line, it is immobilized at the center of the boundary element but remains active to be moved again if conditions allow in future time steps.

In all results shown herein, a horizontal dispersion coefficient, $D$, of $1.5 \mathrm{~m}^{2} / \mathrm{s}$ is used, justifiable by the low velocities experienced throughout the domain (Stocker \& Imberger, 2003; Swain et al., 2004). This choice is also consistent with the work by Piattella et al. (2006), whose shallow water formula $(D=C \cdot d \cdot \sqrt{g d})$ gives approximately $1.56 \mathrm{~m}^{2} / \mathrm{s}$ for the dispersion coefficient with a reference depth $d$ of $1 \mathrm{~m}$ and an experimentally determined dimensionless constant $C$ of 0.5 . A quick Peclet number analysis similar to Takeoka (1984) also showed that for larger coefficients, there is the possibility that the exchange could be dominated by artificial dispersion, an undesired effect. It should also be noted that the horizontal mixing due to wave action is lumped into this dispersion coefficient, which is in the range given by Shen and Zou (2012) and Diez et al. (1998). This shortcoming will be dealt in the future studies as the wave climate will also have an important role in the longshore transport.

The 33 days long simulations exclude a ramp-up time of approximately 1.5 days and use a hydrodynamic model time step of 49.68 seconds. This corresponds to 57392 time steps after the dynamic equilibrium is reached. A Courant-Friedrichs-Levy (CFL) type analysis not based on wave celerity but based on particle velocity was performed to make sure that a particle does not cross several triangular elements during a time step when high velocities are involved. This would cause a particle not to experience the physical effects represented by this computational element. The model time step satisfies this requirement at all elements in the computational domain except the inlets where steps of approximately 20 seconds are needed due to amplified current velocities. This, however, does not alter 
the particle solution since the straight channel geometry and the almost constant bathymetry in the vicinity of the inlets result in particles following linear pathways under constant velocities in and out of the lagoon. It should also be noted that the use of a $4^{\text {th }}$ order Runge-Kutta scheme effectively halves down the sensitivity of the particle tracking solution to approximately 25 seconds. Since the grid quality measure $q$ and CFL tests did not show any anomalies, no further sensitivity analyses were performed on the effect of the grid size.

The simulations are run using 13 to 24 CPU's on HP ProLiant BL2x220c G5 Blade servers using Intel Xeon $2.66 \mathrm{GHz}$ processors. The high resolution run (SIM 6 in Table 2) takes approximately 15 days to complete under dynamic load balancing with "medium" priority. It should be noted that this is not an absolute duration and the simulation may be completed in much less time if run under "high" priority or with no restrictions at all.

Table 1. Tidal forcing components as reported by Alpar and Yuce (1998). These correspond to mean spring and neap ranges of 3.4 and 2.7 centimeters respectively

\begin{tabular}{|c|c|c|c|}
\hline $\begin{array}{c}\text { Tidal } \\
\text { Component }\end{array}$ & $\begin{array}{c}\text { Period } \\
\text { (hours) }\end{array}$ & $\begin{array}{c}\text { Amplitude } \\
(\mathrm{cm})\end{array}$ & $\begin{array}{c}\text { Phase Angle } \\
\left({ }^{\circ}\right)\end{array}$ \\
\hline $\mathrm{M}_{2}$ & 12.42 & 0.84 & 302 \\
\hline $\mathrm{S}_{2}$ & 12.00 & 0.51 & 347 \\
\hline $\mathrm{K}_{1}$ & 23.93 & 0.96 & 162 \\
\hline $\mathrm{O}_{1}$ & 25.82 & 0.74 & 118 \\
\hline
\end{tabular}

\section{Results}

The results are presented in both Eulerian and Lagrangian framework to check consistency. While the former uses residuals to predict overall transport pathways, the latter concentrates on the $e$-folding time as a measure of the exchange.

\subsection{The Eulerian results}

To get an overall idea of the dominant Eulerian transport pathways in and out of the inlets, three stations are chosen at the west, center and east of each of the northern (N1, $\mathrm{N} 2$ and N3 respectively) and southern (S2, S2 and S3 respectively) inlets (Figure 3 ). The current velocities and directions are recorded at each station and plotted over the entire simulation period (Figure 6). Although we do lack measured current data and cannot make quantitative comparisons, the plots still provide important qualitative information that can be used for planning purposes.

As expected, the highest current magnitudes of approximately $0.25 \mathrm{~m} / \mathrm{s}$ are experienced in the channels (N2 and S2). The fact that the highest current magnitudes match the dominant current directions suggests net inward transport through the southern channel and net outward transport through the northern channel. This observation is also confirmed by the residual current vectors calculated and plotted after the first 9 days of the simulations, dominated $90 \%$ of the time by southwesterly winds (Figure 7). The residuals, defined here as the vectorial averages of currents simulated at each node of the computational grid over this period, show that the northern inlet acts like a flushing channel even when southwesterlies are continuously trying to pump sea water into the lagoon. The shallows reflect the dominant effect of these winds by having strong landward residuals around $5 \mathrm{~cm} / \mathrm{s}$. Although not shown here, it should also be mentioned that the residual vectors in the lagoon proper show an overall transport pattern towards the northern inlet in the channels. Over the shallower flats, the net residual transport opposes the transport in the nearing channels with gyres forming in the transitional zones. These all suggest that the net exchange into the lagoon through the more dynamic southern inlet is balanced by the net exchange out of the lagoon through the northern inlet under the given February climatology, probably caused by the northern inlet lagging in response to prevailing winds. We should also point out that the in-lagoon flow patterns and thus the transfer between specific sections of the lagoon will need to be investigated in detail if any anthropogenic activity with heavy environmental impact is planned.

To represent the non-tidal response of the lagoon proper to the changing wind magnitude, we perform a residual analysis. Since there is no residual component in
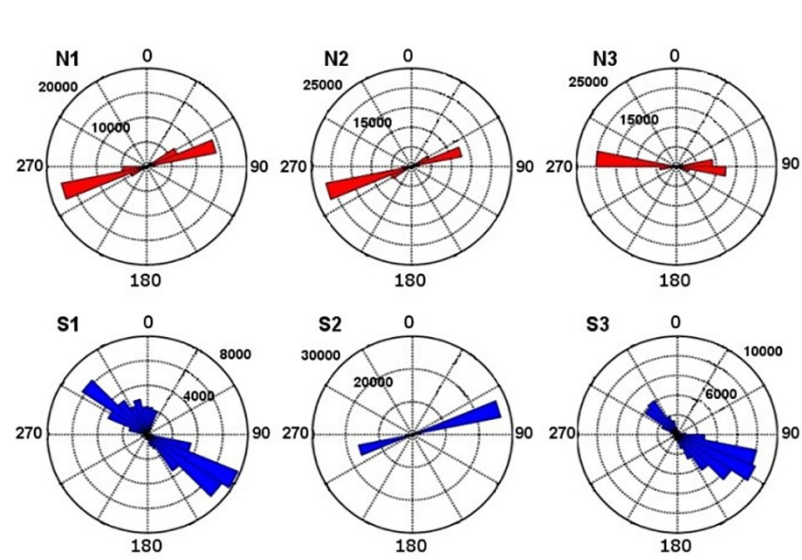

Figure 6. Simulated current velocities and directions at recording stations N1, N2, N3, S1, S2 and S3. The current vector polar plots (left) use radial increments in $\mathrm{m} / \mathrm{s}$. The current direction histogram (right) uses $11.25^{\circ}$ bins 

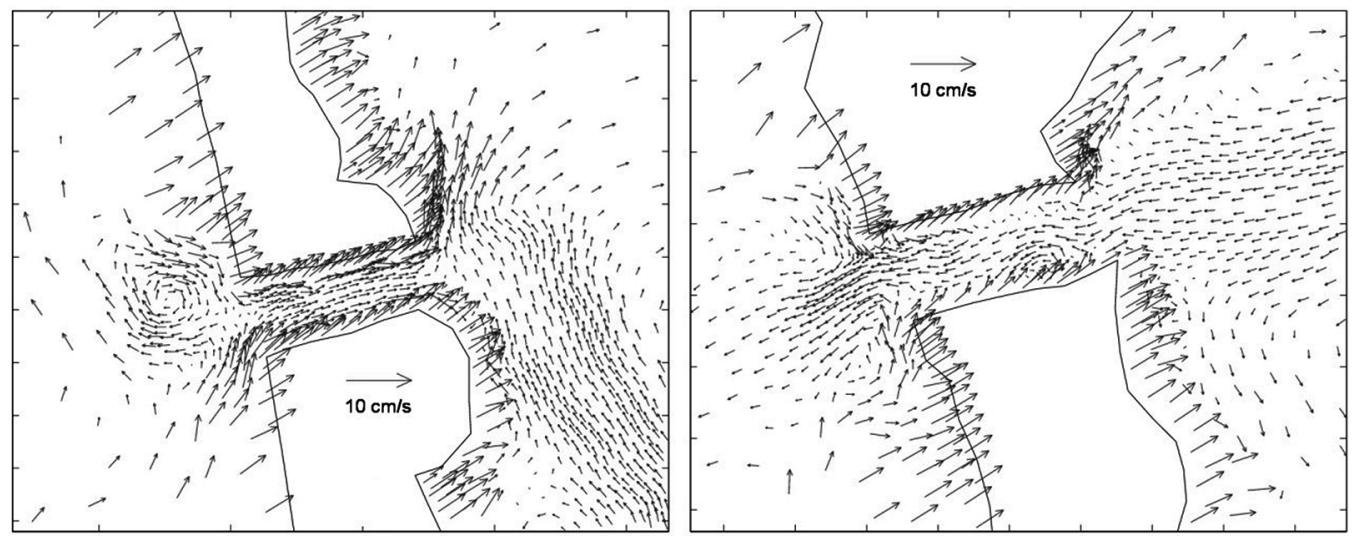

Figure 7. The residual current vectors near the southern (left) and northern (right) inlets after the first 9 days of the simulations

boundary forcing, no density effects and no freshwater input, the residual circulation is expected to be generated by domain geometry, interaction between tidal components and most importantly the wind effects (Guyondet \& Koutitonsky, 2008). To investigate, the residual current time series are extracted at each computational node within the boundaries of the lagoon, including the inlets, using a least-squares harmonic analysis of simulated monthlong velocity component time series at these nodes. The residual current time series so-obtained are then space averaged over all the in-lagoon computational nodes to come up with only one residual time series, which represents the lagoon as a whole entity. A 25.82-hour moving average is then applied to remove the short-term fluctuations and noisiness in the time series and put the emphasis on the daily response, rather than the instantaneous one. Figure 8 shows these space and time averaged residuals plotted against wind magnitudes averaged over the same period. The Pearson correlation coefficient between the two time series is 0.897 , which suggests a strongly wind dominated lagoon system. A similar calculation gives a correlation coefficient of 0.022 between the tidal forcing and the residual currents.

\subsection{The Lagrangian results}

Several approaches are possible to investigate the exchange between the coastal sea and the lagoon, as summarized by Bilgili et al. (2005). Since the lagoon is relatively small and at this initial stage our area of interest is the entire lagoon rather than the specific parts of it, we choose the $e$ folding time, which is a response time-scale for processes exponential in nature, as a measure of flushing (Inoue \& Wiseman, 2000). We simulate a polluted lagoon and a clean sea, i.e. the clean particles that enter the lagoon from the coastal sea during the simulation are not incorporated into the $e$-folding time calculations, partly due to the uncertainty in the tidal boundary conditions. However, the particles that started their lives as polluted particles but leave the lagoon through the inlets are counted continuously in case they return to the lagoon. Consequently the return flow factor, as defined in Cucco et al. (2009) is somewhere between zero and one, with a strong bias towards zero due to the fact that the southern inlet acts as a source and the northern inlet as a sink under southeasterly winds that push the sea water into the lagoon. As stated in Cucco and Umgiesser (2006), the effect of the return flow depends highly on the winds and the strength of the tidal forcing, causing differences up to $30 \%$ in the simulated residence times, thus the incorporation of the calculation of the return flow factor is a must in an operational model. Two cases are considered: a no wind case and a realistic windy case using the measured winds given in Figure 5. As can be seen from Table 2, there are considerable differences in exchange results, with the windy lagoon $e$-folding between 8.96 and 21.9 days as a function of the number of particles used in the simulations. When there is no wind, these values range between 14.3 and 28.2 days. These large ranges that correspond to approximately $144 \%$ and $97 \%$ differences respectively suggest that a procedure should be set up to determine the number of particles necessary to simulate the response of the domain to external forcing within acceptable bounds, a problem already tackled by Graham and Moyeed (2002). We follow a more simplistic but comparable approach below. It is to be noted that

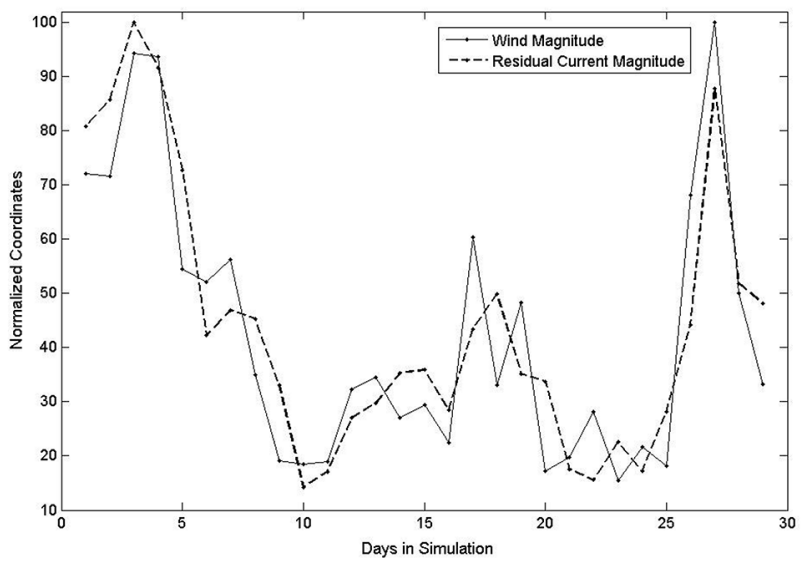

Figure 8. Wind magnitude and lagoon-averaged residual current magnitudes over the duration of the simulation. Both data series are shown using normalized coordinates. The time series are shown averaged over intervals of 25.82 hours $\left(\mathrm{O}_{1}\right.$ principal lunar diurnal tidal component period) 
although the sensitivity of the solutions to the number of particles is a known issue in Lagrangian particle tracking simulations, there is not a wealth of studies specifically addressing this problem, especially in the world of coastal hydrodynamical and ecological simulations. Instead, many modeling studies either use an approach similar to Graham and Moyeed (2002) (Delele et al., 2016; Baudry et al., 2018; Musiu et al., 2019) or just indicate that a "statistically significant" or "large enough" number of particles have been used (Pascal \& Oesterlé, 2000; Smagin et al., 2018; Huggett et al., 2020; Zhang et al., 2020).

Our methodology starts the simulations by filling the entire $4000 \times 2840$ meter domain with an equal number of wet and dry particles $(350 \times 350-$ SIM 1$)$ in $\mathrm{x}$ and $\mathrm{y}$ directions. We then increase the density by using $750 \times 750$, $1000 \times 1000$ and $1500 \times 1500$ particles in SIM2, 3 and 4 respectively. Then the particles on land, islands and coastlines (dry particles) are removed from the simulation after some polygon checks. The last two simulations (SIM 5 and 6) use equal spacing in all directions as a supplementary test of how much additional accuracy would higher numbers of particles bring to the results. The $N$ in Table 2 shows the wet particles only. The initial choice and the progressive increase of $N$ is an ad-hoc decision process based on the convergence of the percent relative errors shown in Table 2. As revealed by the percent relative errors in Table 2, it is expected that as the number of particles $N$ increase, the results converge towards a statistically significant solution, although fluctuations could occur with relatively small increases in $N$. This implies that if a confidence level between two consecutive simulations drops below a certain preset level, then it can be assumed that the optimal number of particles necessary to represent the system is reached and further increases would only add to run time without significantly affecting the accuracy of the solution. The measure that the confidence level will be based on is important and should be somehow related to the key parameters in the region of interest. In our case, we set the confidence level to a $5 \%$ variation in the $e$-folding times of the windy case since we are interested in the flushing response of the entire lagoon under realistic conditions. As shown by the percent relative errors in Table 2, this level is reached between SIM 4 and SIM 5 with a value of $1.5 \%$. Practically this means that the particle results from SIM 4 can be used at a $5 \%$ confidence level in studies concerning the entire lagoon's exchange characteristics in future studies. The $e$-folding times between the windy case and the no-wind case vary between $59.5 \%$ and $125.5 \%$, with the lagoon never $e$-folding in SIM 1. It is also observed that the no-wind case converges later, with a confidence level of 5.9\% reached only between SIM 5 and SIM 6. Based on SIM 5 that has acceptable confidence levels for both cases, the winds cause approximately $59.5 \%$ faster flushing of the lagoon. To conclude this discussion, it should also be noted that approximately $17 \%$ more particles leave the lagoon through the northern inlet than the southern inlet, a result consistent with the Eulerian residuals.

\section{Discussion}

The Eulerian residuals predict inward transport through the southern inlet and outward transport through the northern inlet, even under prevailing southeasterlies. This result is confirmed by the Lagrangian study with $17 \%$ more particles leaving the lagoon through the northern inlet. The lagoon $e$-folds in approximately 9.1 days with a confidence level of $5 \%$. The $e$-folding time increases to approximately 14.3 days under no-wind conditions. The $57.1 \%$ difference between the two simulations suggest a wind dominated system, confirmed by the results of the Eulerian study, which show a strongly wind dominated lagoon with a correlation coefficient of 0.897 between the wind and residual current magnitude time series.

The incorporation of statistically significant Lagrangian studies brings additional reliability or, in certain cases, doubts to the validity of the Eulerian simulations with the additional effect of the Lagrangian residuals. However, the term "statistically significant" is usually tied to the usage of a relatively large number of particles, which itself is typically tied to the available computational resources such as the number of CPU's or the amount of RAM. While it is expected that increasing the sample size would increase accuracy, how much is another question as it is anticipated

Table 2. Variation of the $e$-folding times as a function of the number of particles. The $\mathrm{X}$ and $\mathrm{Y}$ resolutions are the initial distances between individual particles in $\mathrm{x}$ and $\mathrm{y}$ directions. The percent relative error calculations take the solution of the simulation with larger number of particles as truth. The "Windy" case is taken as truth in "With vs. Without Wind" error calculations

\begin{tabular}{|c|c|c|c|c|c|c|c|c|}
\hline $\begin{array}{c}\text { Simu- } \\
\text { lation }\end{array}$ & $\begin{array}{c}\text { N, Number } \\
\text { of Particles }\end{array}$ & $\begin{array}{c}\text { X Reso- } \\
\text { lution } \\
\text { (meters) }\end{array}$ & $\begin{array}{c}\text { Y Resolution } \\
\text { (meters) }\end{array}$ & $\begin{array}{c}\text { Lagoon with } \\
\text { Wind } \\
\text { E-Folding } \\
\text { Time (days) }\end{array}$ & $\begin{array}{c}\text { Windy Case } \\
\text { Percent } \\
\text { Relative } \\
\text { Error }\end{array}$ & $\begin{array}{c}\text { Lagoon without } \\
\text { Wind } \\
\text { E-Folding Time } \\
\text { (days) }\end{array}$ & $\begin{array}{c}\text { No Wind } \\
\text { Case Percent } \\
\text { Relative } \\
\text { Error }\end{array}$ & $\begin{array}{c}\text { With vs. } \\
\text { Without Wind } \\
\text { Percent Relative } \\
\text { Error }\end{array}$ \\
\hline SIM 1 & 65073 & 11.3 & 8.4 & 21.9 & $72.4 \%$ & - & - & - \\
\hline SIM 2 & 299771 & 5.3 & 3.8 & 12.7 & $29.5 \%$ & 28.2 & $27.6 \%$ & $122.0 \%$ \\
\hline SIM 3 & 464257 & 4.0 & 2.8 & 9.8 & $7.6 \%$ & 22.1 & $18.1 \%$ & $125.5 \%$ \\
\hline SIM 4 & 783823 & 2.7 & 1.9 & 9.1 & $1.5 \%$ & 18.7 & $30.7 \%$ & $105.4 \%$ \\
\hline SIM 5 & 1534778 & 2.0 & 2.0 & 8.96 & $0.2 \%$ & 14.3 & $5.9 \%$ & $59.5 \%$ \\
\hline SIM 6 & 2730486 & 1.5 & 1.5 & 8.98 & - & 15.2 & - & $69.2 \%$ \\
\hline
\end{tabular}


to vary greatly between domains and physical conditions and parameters, leading to large relative errors. For instance, a relatively large sample size of approximately 300000 particles (SIM 2) fails to represent the exchange characteristics of this relatively small domain. Here, we present a practical and relatively simple way to quantify a Lagrangian particle release simulation's convergence in exchange calculations. The simple methodology consists of increasing the number of particles until the confidence level between two consecutive simulations fall below a certain preset value. The number of elements used to discretize the domain can be used as a first approximation since it is at least a representation of the space scales. Then this number can be increased in a controlled manner until a "large enough" (i.e. 30 for normal distribution) number of particles initiate from each element. The confidence level should be imposed on the physical variable of interest, such as the $e$-folding time, the Markovian first passage time or the flushing time to name a few. It is observed that, for this specific case, approximately 784000 particles are necessary to obtain $5 \%$ level of confidence. The inclusion of a convergence criterion similar to the one presented here in applied particle tracking simulations would increase the reliability and validity of this otherwise very useful method.

We have to emphasize here that the Lagrangian method is an "experimental" tool to approximate the truth. It is this experimental nature that gives rise to the necessity of checking the sensitivity of the solution to the number of particles (Simons et al., 2013). There are other methods (many of which the derivations of the Eulerian advective-dispersive type schemes) that behave well, although known problems such as oscillations and artificial dispersion may occur in the vicinity of sharp fronts (Eheart, 2006; Chen \& Zhang, 2007; Sofiev et al., 2015). Arega and Badr (2010) report that both the Eulerian tracer age method (Deleersnijder et al., 2001; Andutta et al., 2014) and the Lagrangian particle tracking method provide comparable solutions to the residence time problem of a small tidal creek in the tidally averaged sense. They also report that the Lagrangian method shows a more detailed distribution of the gradients

\section{Conclusions}

The Kamil Abdus Lagoon provides an excellent open ground for studying the anthropogenic effects on coastal lagoons. It is highly engineered with disastrous environmental consequences and it is now being recreated due to its socio-economic importance for the region. The initial intended use was to use it as a natural recreational site open to public with farming of the glasswort (Salicornia europaea) on the islands. There are now several other proposed activities such as aquaculture and marina operations, both requiring a larger and more protected water area. The latter is the reason why the islands were arbitrarily relocated in the present configuration, which will be used in all future work. The recently proposed activities all come with environmentally high-risk levels and will ideally need extensive research under current environmental regulations.

This study is a preliminary diagnostic effort to contribute to future managerial decision-making processes in case no further investigations are possible due to lack of funding. We now have a description of the typical velocities, transport pathways and residual flow throughout the domain, all of which can be used towards the reconfiguration of geographic entities such as the inlets, the islands and the deeper channels. The information can also be used in location selection for planned activities, especially the high-risk ones such as the aquaculture, for which one would choose a location that has a direct path out of the lagoon, i.e. the northern inlet. The e-folding time, in its turn, is a transport time scale of how efficiently the lagoon flushes out the introduced material, thus it is a key management tool that dictates how much of a pollutant load the lagoon can tolerate before the concentrations increase to potentially unsafe levels for the ecosystem. Any newly planned activity should use this information ( 9 and 15 days for with and without wind cases respectively) to determine how much waste can be produced before the maximum allowable limit is reached. The same idea also applies to natural events such as eutrophication in which case the e-folding time can be used as an emergency tool to plan recovery activities. It should also be noted that an additional advantage comes from the diagnostic nature of the simulations, which helps in the planning of future activities. For instance, a scheme can be generated from the simulated velocity field to decide on the number and location of possible current measurements to validate the model using the relative ratio between the simulated current magnitudes. We emphasize once again that the overall purpose of the current paper is to present an initial effort. We tried to keep the study simple but useful for managerial purposes to keep the science in the loop, given the understanding that errors will exist in quantitative deductions. A validated operational prognostic model would need to investigate other important phenomena, including but not limited to the effect of the return flow, the temporal variability of the residence time and the wind setup and set-down. The latter is especially important since storm surges have the potential to modify the circulation patterns in the lagoon and in and out of the inlets considerably, as emphasized in Zecchetto et al. (1997).

The disconnection between science and management is a traditional problem in environmental matters, especially in the modelling field (Chagaris et al., 2019; Schuwirth et al., 2019). As highlighted in Gosselin et al. (2018), even beliefs, opinions and other non-scientific representations can become a part of the knowledge base in the decision making process. We believe that diagnostic methods such as the one we presented here can easily find themselves a place in Gosselin et al. (2018) ecological knowledge chart as another bridge between empirical and scientific knowledge. As funding becomes scarce, especially for local coastal systems such as the one mentioned in 
this paper, researchers are further faced to work with limited resources and managers are further restricted to make decisions with incomplete data. We strongly believe that this situation should not keep a real world problem from being worked on and an optimal solution should be obtained within error limits. In this study, we tried to resolve the overall flow patterns and exchange characteristics and present them as what they are since we lack data to quantitatively verify model results and resolve the small-scale patterns. Although this may sound rough, it is important to note that this still provides a way of keeping the scientific research in the loop and most importantly document it in a decision process that would otherwise be random. The arbitrary relocation of the islands between the start and the termination of this study is a prime example of that. By default, it is expected that there will be a lack of financial assets to fund long-term scientific studies, forcing scientists, engineers and planners to work cooperatively with limited resources and data. In this sense, the lagoon will set a dynamic and step by step example on how similar systems should be planned and managed sustainably over time and it will be valuable to see how the present performance will scale with future research as data becomes available and fed into the model. The methodology to evaluate the results of the Lagrangian particle tracking simulations, however, is case-independent and it can be applied to any system to evaluate and report its effectiveness in selecting a "statistically significant" number of particles.

\section{Acknowledgements}

We would like to thank the Municipality of the Tuzla District of Istanbul, Turkey, for giving us the opportunity to work on this project and for providing us with the lagoon configuration information and maps. Dr. Daniel R. Lynch (emer., Dartmouth College) is also acknowledged for the use of the numerical model and for his very valuable contributions throughout the years. This work was partly supported by the City of Istanbul Metropolitan Municipality under the "My Project Istanbul" program. The parallel simulations were performed using the clusters at the Istanbul Technical University National High Performance Computing Center through project \#1001192011.

\section{References}

Alpar, B., \& Yuce, H. (1998). Sea-level variations and their interactions between the Black Sea and the Aegean Sea. Estuarine Coastal and Shelf Science, 46(5), 609-619.

https://doi.org/10.1006/ecss.1997.0285

Andutta, F. P., Ridd, P. V., Deleersnijder, E., \& Prandle, D. (2014). Contaminant exchange rates in estuaries - New formulae accounting for advection and dispersion. Progress in Oceanography, 120, 139-153.

https://doi.org/10.1016/j.pocean.2013.08.009

Arega, F., \& Badr, A. (2010). Numerical age and residence-time mapping for a small creek: Case study. Journal of Waterway, Port, Coastal, and Ocean Engineering, 136(4), 226-237. https://doi.org/10.1061/(ASCE)WW.1943-5460.0000041
Baudry, J., Dumont, D., \& Schloss, I. R. (2018). Turbulent mixing and phytoplankton life history: A Lagrangian versus Eulerian model comparison. Marine Ecology Progress Series, 600, 55-70. https://doi.org/10.3354/meps12634

Bilgili, A., Swift, M. R., Lynch, D. R. \& Ip, J. T. C. (2003). Modeling bed-load transport of coarse sediments in the Great Bay Estuary, New Hampshire. Estuarine, Coastal and Shelf Science, 58(4), 937-950. https://doi.org/10.1016/j.ecss.2003.07.007

Bilgili, A., Proehl, J. A., Lynch, D. R., Smith, K. W., \& Swift, M. R. (2005). Estuary/Ocean exchange and tidal mixing in a Gulf of Maine Estuary: A Lagrangian modeling study. Estuarine Coastal and Shelf Science, 65(4), 607-624. https://doi.org/10.1016/j.ecss.2005.06.027

Bilgili, A., Smith, K. W., \& Lynch, D. R. (2006). BatTri: A twodimensional bathymetry-based unstructured triangular grid generator for finite element circulation modeling. Computers \& Geosciences, 32(5), 632-642. https://doi.org/10.1016/j.cageo.2005.09.007

Bilgili, A., Proehl, J. A., \& Swift, M. R. (2016). Dredging for dilution: A simulation based case study in a Tidal River. Journal of Environmental Management, 167, 85-98. https://doi.org/10.1016/j.jenvman.2015.11.008

Blanton, B. O. (1995). Drog3d: User's manual for 3-dimensional drogue tracking on a finite element grid with linear finite elements. University of North Carolina at Chapel Hill.

Chagaris, D., Sagarese, S., Farmer, N., Mahmoudi, B., De Mutsert, K., Vanderkooy, S., Patterson, W. F., Kilgour, M., Schueller, A., Ahrens, R., \& Lauretta, M. (2019). Management challenges are opportunities for fisheries ecosystem models in the Gulf of Mexico. Marine Policy, 101, 1-7. https://doi.org/10.1016/j.marpol.2018.11.033.

Chen, Q., \& Zhang, Z. (2007). Comparison of the Eulerian and Lagrangian methods for predicting particle transport in enclosed spaces. Atmospheric Environment, 41(25), 5236-5248. https://doi.org/10.1016/j.atmosenv.2006.05.086

Cucco, A., \& Umgiesser, G. (2006). Modeling the Venice Lagoon residence time. Ecological Modelling, 193(1-2), 34-51. https://doi.org/10.1016/j.ecolmodel.2005.07.043

Cucco, A., Umgiesser, G., Ferrarin, C., Perilli, A., Canu, D. M., \& Solidoro, C. (2009). Eulerian and Lagrangian transport time scales of a tidal active coastal basin. Ecological Modelling, 220(7), 913-922.

https://doi.org:/10.1016/j.ecolmodel.2009.01.008

Deleersnijder, E., Campin, J. M., \& Delhez, E. J. M. (2001). The concept of age in marine modeling. I. Theory and preliminary model results. Journal of Marine Systems, 28(3-4), 229-267. https://doi.org/10.1016/S0924-7963(01)00026-4

Delele, M. A., Jaeken, C., Debaer, C., Baetens, K., Melese Endalew, A., Ramon, H., Nicola, B. M., \& Verboven, P. (2016). CFD prototyping of an air-assisted orchard sprayer aimed at drift reduction. Computers and Electronics in Agriculture, 55(1), 16-27. https://doi.org/10.1016/j.compag.2006.11.002

Delhez, E. J. M., De Brye, B., De Brauwere, A., \& Deleersnijder, E. (2014). Residence time vs influence time. Journal of Marine Systems, 132, 185-195.

https://doi.org/10.1016/j.jmarsys.2013.12.005

Dias, J. M., Lopes, J. F., \& Dekeyser, I. (2001). Lagrangian transport of particles in Ria de Aveiro lagoon, Portugal. Physics and Chemistry of the Earth, Part B: Hydrology, Oceans and Atmosphere, 26(9), 721-727. https://doi.org/10.1016/S1464-1909(01)00076-4

Diez, M., Mösso, C., Sierra, J. P., Mestres, M., Sanchez-Arcilla, A., Rodriguez, A., Bezerra, M. O., \& Redondo, J. M. (1998). Estimation of dispersion coefficients in low wave energy surf 
zone using video images. In Proceedings of the $4^{\text {th }}$ International Conference Littoral 98 (pp. 535-542), Barcelona, Spain.

Edwards, K. P., Hare, J. A., Werner, F. E., \& Blanton, B. O. (2006). Lagrangian circulation on the Southeast US Continental Shelf: Implications for larval dispersal and retention. Continental Shelf Research, 26(12-13), 1375-1394.

https://doi.org/10.1016/j.csr.2006.01.020

Eheart, J. W. (2006). Some numerical properties of explicit solutions to the one-dimensional conservation equation. Water International, 31(2), 252-258. https://doi.org/10.1080/02508060.2006.9709675

Erturk, S. N., Bilgili, A., Swift, M. R., Brown, W. S., Çelikkol, B., Ip, J. T. C., \& Lynch, D. R. (2002). Simulation of the Great Bay Estuarine System: Tides with tidal flats wetting and drying. Journal of Geophysical Research: Oceans, 107(5), 6-1-6-10. https://doi.org/10.1029/2001JC000883

Ferrarin, C., Bellafiore, D., Sannino, G., Bajo, M., \& Umgiesser, G. (2018). Tidal dynamics in the inter-connected Mediterranean, Marmara, Black and Azov seas. Progress in Oceanography, 161, 102-115. https://doi.org/10.1016/j.pocean.2018.02.006

Fugate, D. C., Friedrichs, C. T., \& Bilgili, A. (2006). Estimation of residence time in a shallow back barrier lagoon, Hog Island Bay, Virginia, USA. In Proceedings of the $8^{\text {th }}$ International Conference on Estuarine and Coastal Modeling (pp. 319-337). Charleston, South Carolina. https://doi.org/10.1061/40876(209)19

Graham, D. I., \& Moyeed, R. A. (2002). How many particles for my Lagrangian simulations. Powder Technology, 125(2-3), 179-186. https://doi.org/10.1016/S0032-5910(01)00504-6

Gosselin, F., Cordonnier, T., Bilger, I., Jappiot, M., Chauvin, C., \& Gosselin, M. (2018). Ecological research and environmental management: We need different interfaces based on different knowledge types. Journal of Environmental Management, 218, 388-401. https://doi.org/10.1016/j.jenvman.2018.04.025.

Guyondet, T., \& Koutitonsky, V. G. (2008). Tidal and residual circulations in coupled restricted and Leaky Lagoons. Estuarine Coastal and Shelf Science, 77(3), 396-408. https://doi.org/10.1016/j.ecss.2007.10.009

Harms, I. H., Karcher, M. J., \& Burchard, H. (2003). Modelling radioactivity in the marine environment: The application of hydrodynamic circulation models for simulating oceanic dispersion of radioactivity. In E. M. Scott (Ed.), Modelling radioactivity in the environment (Vol. 4, pp. 55-85). Elsevier. https://doi.org/10.1016/S1569-4860(03)80059-1

Hoyer, A. B., Wittman, M. E., Chandra, S., Schladow, S. G., \& Rueda, F. J. (2014). A 3D individual-based aquatic transport model for the assessment of the potential dispersal of Planktonic Larvae of an Invasive Bivalve. Journal of Environmental Management, 145(12), 330-340.

https://doi.org/10.1016/j.jenvman.2014.05.011

Huggett, R. D., Purdie, D. A., \& Haigh, I. D. (2020). Modelling the influence of Riverine inputs on the circulation and flushing times of small shallow estuaries. Estuaries and Coasts, 44, 54-69. https://doi.org/10.1007/s12237-020-00776-3

Inoue, M., \& Wiseman Jr., W. J. (2000). Transport, mixing and stirring processes in a Louisiana estuary: A model study. Estuarine, Coastal and Shelf Science, 50(4), 449-466. https://doi.org/10.1006/ecss.2000.0587

Ip, J. T. C., Lynch, D. R., \& Friedrichs, C. T. (1998). Simulation of estuarine flooding and dewatering with application to Great Bay, New Hampshire. Estuarine Coastal and Shelf Science, 47(2), 119-141. https://doi.org/10.1006/ecss.1998.0352

Larson, M. R., Foreman, M. G. G., Levings, C. D., \& Tarbotton, M. R. (2003). Dispersion of discharged ship ballast water in Vancouver Harbor, Juan De Fuca Strait, and offshore of the Washington Coast. Journal of Environmental Engineering and Science, 2(3), 163-176. https://doi.org/10.1139/S03-014

Lynch, D. R., Greenberg, D. A., Bilgili, A., McGillicuddy Jr., D. J., Manning, J. P., \& Aretxabaleta, A. L. (2015). Particles in the coastal ocean: Theory and applications. Cambridge University Press. https://doi.org/10.1017/CBO9781107449336

McLaughlin, J. M., Bilgili, A., \& Lynch, D. R. (2003). Numerical modeling of tides in the Great Bay Estuarine System: Dynamical balance and spring-neap residual modulation. Estuarine, Coastal and Shelf Science, 57(1-2), 283-296. https://doi.org/10.1016/S0272-7714(02)00355-4

Musiu, E. M., Qi, L., \& Wu, Y. (2019). Evaluation of droplets size distribution and velocity pattern using Computational Fluid Dynamics modelling. Computers and Electronics in Agriculture, 164. https://doi.org/10.1016/j.compag.2019.104886

Ozbahceci, B. O. (2020). Extreme value statistics of wind speed and wave height of the Marmara Sea based on combined radar altimeter data. Advances in Space Research, 66(10), 23022318. https://doi.org/10.1016/j.asr.2019.08.025

Ozturk, H. (2005). Metropolitan development on drought history of the Tuzla Lake, Istanbul, Turkey. Journal of Coastal Research, 212, 255-262. https://doi.org/10.2112/03-0074.1

Pascal, P., \& Oesterlé, B. (2000). On the dispersion of discrete particles moving in a turbulent shear flow. International Journal of Multiphase Flow, 26(2), 293-325. https://doi.org/10.1016/S0301-9322(99)00019-1

Piattella, A., Brocchini, M., \& Mancinelli, A. (2006). Topographically controlled, breaking-wave-induced macrovortices. Part 3. The mixing features. Journal of Fluid Mechanics, 559, 81-106. https://doi.org/10.1017/S0022112006009918

Qin, X., Van Sebille, E., \& Gupta, A. S. (2014). Quantification of errors by temporal resolution on Lagrangian particles in an Eddy-Resolving model. Ocean Modelling, 76(C), 20-30. https://doi.org/10.1016/j.ocemod.2014.02.002

Schuwirth, N., Borgwardt, F., Domisch, S., Friedrichs, M., Kattwinkel, M., Kneis, D., Kuemmerlen, M., Langhans, S. D., Martínez-López, J., \& Vermeiren, P. (2019). How to make ecological models useful for environmental management. Ecological Modelling, 411, 108784.

https://doi.org/10.1016/j.ecolmodel.2019.108784

Shen, L. D., \& Zou, Z. L. (2012). Study and verification on dispersion coefficient in wave field. Science China Technological Sciences, 55(5), 1443-1454.

https://doi.org/10.1007/s11431-012-4770-4

Simons, R. D., Siegel, D. A., \& Brown, K. S. (2013). Model sensitivity and robustness in the estimation of larval transport: A study of particle tracking parameters. Journal of Marine Systems, 119-120, 19-29. https://doi.org/10.1016/j.jmarsys.2013.03.004

Smagin, K. A., Khrenov, S. I., \& Timofeev, E. M., (2018). Statistical aspects of particle behaviour in industrial electrostatic precipitators. In International Conference on Industrial Engineering, Applications and Manufacturing (ICIEAM) (pp. 1-5). IEEE. https://doi.org/10.1109/ICIEAM.2018.8728742

Sofiev, M., Vira, J., Kouznetsov, R., Prank, M., Soares, J., \& Genikhovich, E. (2015). Construction of an Eulerian atmospheric dispersion model based on the advection algorithm of M. Galperin: Dynamic cores v.4 and 5 of SILAM v.5.5. Geoscientific Model Development Discussions, 8, 2905-2947. https://doi.org/10.5194/gmdd-8-2905-2015

Stocker, R., \& Imberger, J. (2003). Horizontal transport and dispersion in the surface layer of a medium sized lake. Limnology and Oceanography, 48(3), 971-982.

https://doi.org/10.4319/lo.2003.48.3.0971 
Swain, E. D., Wolfert, M. A., Bales, J. D., \& Goodwin, C. R. (2004). Two dimensional hydrodynamic simulation of surfacewater flow and transport to Florida Bay through the Southern Inland and Coastal Systems (SICS) (US Geological Survey Water-Resources Investigations Report 2003-4287). https://doi.org/10.3133/wri034287

Swanson, C., Bilgili, A., \& Lynch, D. (2015). Long-term simulations of wastewater treatment facility discharges into the Great Bay Estuarine System (New Hampshire). Water Quality, Exposure and Health, 7(1), 67-77. https://doi.org/10.1007/s12403-014-0132-8

Takeoka, H. (1984). Fundamental concepts of exchange and transport time scales in a coastal sea. Continental Shelf Research, 3(3), 311-326.

https://doi.org/10.1016/0278-4343(84)90014-1

Tansel, B. (2010). High quality triangular grid generation for the risk analysis of a special lagoon. In M. Rahman \& C. A. Brebbia (Eds.), Proceedings of the advances in fluid mechanics VIII (pp. 231-240). WIT Press.

https://doi.org/10.2495/AFM100201
$\mathrm{Wu}, \mathrm{J}$. (1982). Wind-stress coefficients over sea surface from breeze to hurricane. Journal of Geophysical Research, 87(C12), 9704-9706. https://doi.org/10.1029/JC087iC12p09704

Zecchetto, S., Umgiesser, G., \& Brocchini, M. (1997). Hindcast of a storm surge induced by local real wind fields in the Venice Lagoon. Continental Shelf Research, 17(12), 1513-1538. https://doi.org/10.1016/S0278-4343(97)00023-X

Zhang, L., Chen, L., Zhou, J., Wang, J., Yang, Q., \& Han, L. (2020). Development and application of a new random walk model to simulate the transport of degradable pollutants. Journal of Hydrodynamics, 32(4), 784-789. https://doi.org/10.1007/s42241-020-0048-7

Zheng, L., Weisberg, R. H., Huang, Y., Luettich, R. A., Westerink, J. J., Kerr, P. C., Donahue, A. S., Crane, G., \& Akli, L. (2013). Implications from the comparisons between two- and three- dimensional model simulations of the Hurricane Ike storm surge. Journal of Geophysical Research: Oceans, 118(7), 3350-3369. https://doi.org/10.1002/jgrc.20248 